\title{
An Opioidergic Cortical Antinociception Triggering Site in the Agranular Insular Cortex of the Rat that Contributes to Morphine Antinociception
}

\author{
Adam R. Burkey, ${ }^{1}$ Earl Carstens, ${ }^{2}$ Julia J. Wenniger, ${ }^{1}$ Jinwen Tang, ${ }^{1}$ and L. Jasmin ${ }^{1}$ \\ ${ }^{1}$ Departments of Neurosurgery and Cell Biology, Georgetown University Medical Center PHC1, Washington, DC 20007, \\ and ${ }^{2}$ Section of Neurobiology, Physiology and Behavior, University of California at Davis, Davis, California 95616
}

\begin{abstract}
We report an anatomically defined opioid-responsive site in the rostral agranular insular cortex (RAIC) of the rat and characterize the antinociception produced by morphine acting within this region. Immunohistochemistry for the $\mu$-opioid receptor identified a discretely localized cluster of densely labeled dendritelike processes in the agranular insular cortex. The antinociceptive effect of morphine microinjected unilaterally into this area was evaluated using the formalin test. Antinociception was observed in both ipsilateral and contralateral hindpaws. Local pretreatment with naltrexone in the RAIC blocked the antinociception of local morphine injection, confirming that morphine was acting at an opioid receptor. Unilateral injection of naloxone methiodide into the RAIC reversed the behavioral antinociception of systemic morphine bilaterally in the formalin test. Evidence for a descending inhibitory mechanism acting on spinal nociceptive neurons was obtained by monitoring noxious stimulus-induced $c$-fos expression in rats having undergone
\end{abstract}

formalin testing and by electrophysiological recording of single units in the lumbar dorsal horn after localized application of morphine into the RAIC. A significant reduction in the number of Fos-like immunoreactive neurons was found ipsilateral to the formalin stimulus in nociresponsive areas of the dorsal horn after on-site injections of morphine into the RAIC. Electrophysiological recording of nociresponsive dorsal horn neurons demonstrated a naloxone-reversible reduction in noxious thermal stimulus-evoked firing after morphine injection into this same area. These results suggest that the RAIC contributes to opioidreceptor-mediated antinociception after either local or systemic morphine administration and that these effects may be associated with an increased descending inhibition of dorsal horn neurons.

Key words: cerebral cortex; systemic opioids; limbic system; descending inhibition; analgesia; pain; Fos; $\mu$-opioid receptor; formalin test
It is well established that systemic morphine produces antinociception in part through the activation of supraspinal systems that inhibit spinal nociresponsive neurons through descending projections (Yeung and Rudy, 1980; Basbaum and Fields, 1984). For instance, it has been shown that certain brainstem structures including the periaqueductal gray matter, rostral ventral medulla (RVM), and the locus coeruleus can produce descending inhibition in response to locally administered morphine and, conversely, that lesions of these areas will attenuate the antinociceptive effect of systemic morphine (Basbaum et al., 1976; Fields et al., 1983; Basbaum and Fields, 1984; Heinricher et al., 1994).

The contribution of structures rostral to the brainstem in the production of opioid-induced antinociception has only begun to be described. The central nucleus of the amygdala and the cerebral cortex have been implicated in opioid-induced antinociception (d'Amore et al., 1991; Manning and Mayer, 1995a,b; Matthies and Franklin, 1995). The inhibition of spinal nociceptive neurons by a local action of opioids within these structures, however, has not yet been established. Evidence that the rostral forebrain could modulate nociception through a descending inhibitory mechanism

\footnotetext{
Received March 18, 1996; revised July 25, 1996; accepted July 30, 1996.

This work was supported by National Institutes of Health Grant RO1DK47523-01. A.R.B. is a Howard Hughes Medical Student Fellow. We thank Mr. Daniel Fitzsimmons and Dr. Honghzi Guo for their assistance with immunohistochemistry and surgeries.

Correspondence should be addressed to Dr. L. Jasmin, Departments of Neurosurgery and Cell Biology, Georgetown University Medical Center PHC1, 3800 Reservoir Road, NW, Washington, DC 20007.

Copyright (C) 1996 Society for Neuroscience $0270-6474 / 96 / 166612-12 \$ 05.00 / 0$
}

comes from previous electrophysiological studies (Sessle et al., 1981; Carstens et al., 1982), in which stimulation of specific sites reduced the firing of single nociresponsive spinal neurons. Alternatively, it has been proposed that morphine acting within the forebrain could alter the local processing of nociceptive messages such that they are not perceived as painful (Cohen et al., 1984).

We sought a possible cortical substrate for morphine-induced antinociception using immunohistochemistry for the $\mu$ - and $\kappa$-opioid receptors. The perirhinal cortex has been reported to be involved in opioid antinociception (d'Amore et al., 1991), and the insular cortex, in particular, is known to receive viscerotopic sensory input (Cechetto and Saper, 1987). An unusually high density of $\mu$-opioid receptor immunoreactivity in the rostral agranular insular cortex (RAIC), therefore, appeared to be a likely candidate for morphine's action on sensory processing. The antinociceptive effect of morphine microinjection within and around this region was assessed by formalin test behavior. The opioid-receptor dependence of this effect was verified by pretreatment with local naltrexone before morphine administration through the same guide cannula. To ascertain the involvement of the RAIC in systemic morphine-induced antinociception, naloxone methiodide was injected locally to attempt reversal of systemic morphine-induced antinociception during a formalin test. Finally, to determine the possible involvement of a descending inhibitory mechanism, formalin test behavior was correlated with the degree of $c$-fos expression as a marker of noxious stimulusevoked activity in spinal nociresponsive neuron populations. Electrophysiological recording was used for direct verification of the 


\begin{tabular}{llr}
\hline Table 1. Summary of experimental protocols & & Number of animals \\
Experiments & Drugs: dose and volume & 108 \\
\hline Formalin behavior (total) & & 58 contralateral; 13 ipsilateral \\
$\quad$ After morphine sulfate in RAIC & $0.26 \mathrm{nmol} / 200 \mathrm{nl}$ & 11 contralateral; 4 ipsilateral \\
$\quad$ Systemic morphine followed by naloxone methiodide & $5 \mathrm{mg} / \mathrm{kg}$ morphine, s.c., $0.36 \mathrm{nmol} / 200 \mathrm{nl}$ naloxone & \\
$\quad$ in RAIC & methiodide & 15 contralateral \\
$\quad$ Local naltrexone followed by morphine in RAIC & $0.11 \mathrm{nmol} / 200 \mathrm{nl}$ naltrexone hydrochloride; 0.26 & 7 contralateral \\
& nmol/200 nl morphine sulfate & 20 \\
$\quad$ Saline, pH 7.4, in RAIC & $200 \mathrm{nl}$ & 15 \\
Motor/paw-withdrawal tests (total) & $0.26 \mathrm{nmol} \mathrm{in} 200 \mathrm{nl}$ & 5 \\
$\quad$ After morphine sulfate in RAIC & $200 \mathrm{nl}$ & 12 \\
$\quad$ After saline in RAIC & $0.13 \mathrm{or} 0.26 \mathrm{nmol} \mathrm{in} 200 \mathrm{nl}$ & 12 \\
Electrophysiology (total) & $0.825 \mathrm{nmol} \mathrm{in} 200 \mathrm{nl}$ & 12 \\
$\quad$ Injection of morphine sulfate in RAIC & & 140 \\
$\quad$ Followed by naloxone injection in the same site & &
\end{tabular}

inhibitory effect of cortical morphine on the activity of individual spinal nociresponsive neurons.

Preliminary data have been presented previously in abstract form (Wenniger et al., 1994; Marchand et al., 1995).

\section{MATERIALS AND METHODS}

One hundred forty male Sprague Dawley rats (270-320 gm) (Harlan Sprague Dawley, Indianapolis, IN) were used in the study. All animals were exposed to light $12 \mathrm{hr}$ per day (6 A.M. to 6 P.M.); food and water were available ad libitum. Procedures for the maintenance and use of the experimental animals conformed to the regulations of the Georgetown University and University of California at Davis Committees on Animal Research and were carried out in accordance with the guidelines of the National Institutes of Health regulations on animal use.

\section{Intracerebral microinjections}

Stainless steel cannulae were used for all injections (Plastics One). Two days before testing, the animals were anesthetized with a mixture of $1.0 \%$ halothane and $40 \%$ oxygen, and a 26 gauge guide cannula extending 0.5 $\mathrm{mm}$ below the calvarium was implanted stereotaxically through a burr hole over the target area using coordinates from the atlas of Paxinos and Watson (1986) (rostro-caudal, 11.0; lateral, 3.5; dorso-ventral, 2.6). The guide cannula was fixed to the skull with three microscrews and dental cement. On the day of testing, a 33 gauge internal cannula extending 6.2 $\mathrm{mm}$ beyond the end of the guide cannula was inserted. Drugs (Table 1) dissolved in PBS, $\mathrm{pH} 7.4$, were injected through polyethylene tubing connected to the injection cannula (PE-50) (inner diameter, $0.58 \mathrm{~mm}$ ) using a $1.0 \mu \mathrm{l}$ Hamilton syringe driven by a microinfusion pump. The infusion was made at constant speed over a period of $1 \mathrm{~min}$, after which the polyethylene tube was cut and the cannula left in place.

\section{Formalin testing}

Five minutes after agranular insular cortex injection of morphine $(0.26$ $\mathrm{nmol}$ in $200 \mathrm{nl}$ of PBS), pH 7.4, or the vehicle (Table 1), $50 \mu \mathrm{l}$ of $2.0 \%$ formalin in $0.1 \mathrm{M}$ PBS, $\mathrm{pH} 7.4$, was injected subcutaneously in the plantar aspect of the rat's hindpaw with a 30 gauge needle. Formalin injections were made either contralateral $(n=57)$ or ipsilateral $(n=13)$ to the site of intracerebral morphine, or the animal underwent contralateral vehicle injection $(n=7)$. The animal then was placed into a $40 \mathrm{~cm} \times 20 \mathrm{~cm}$ Plexiglas box, under which a mirror angled at $45^{\circ}$ allowed visualization of the plantar aspect of the paws. The rat's response to the nociceptive stimulus was scored by quantifying the time the affected paw was lifted partially or completely as well as licked, shaken, or bitten (Dubuisson and Dennis, 1977). This behavior was monitored continuously for $1 \mathrm{hr}$ by a treatment-blind observer and scored using a computer program developed by Dr. Terrence Coderre (Montréal, Canada), which averages the time spent in each of four formalin behavioral categories: score 0 , normal gait with full weight placed on the injected paw with the toes splayed; score 1 , injected paw rests lightly on the floor with the toes not splayed; score 2 , injected paw clearly elevated from the floor; score 3 , injected paw held off the floor, and the animal licks, shakes, and/or bites it.

In a different experimental group, naltrexone hydrochloride $(0.11$ $\mathrm{nmol} / 200 \mathrm{nl})(n=4)$ or saline $(n=3)$ was injected $10 \mathrm{~min}$ before local morphine administration through the same guide cannula. Biotin dextran $(0.05 \%)$ was added to the morphine solution. Postmortem histochemistry for this tracer allowed confirmation of the morphine injection sites (Brandt and Apkarian, 1992).

One hour after the formalin stimulus, the rats were deeply anesthetized intramuscularly with a mixture of ketamine $(87 \mathrm{mg} / \mathrm{kg})$ and xylazine $(13$ $\mathrm{mg} / \mathrm{kg}$ ) and immediately perfused transcardially with $0.05 \mathrm{M}$ PBS, $\mathrm{pH} 7.4$, followed by $0.1 \mathrm{M}$ phosphate buffered, $\mathrm{pH} 7.4,10 \%$ formalin ( $4 \%$ formaldehyde). The brain and spinal cord were removed and post-fixed in formalin for $4 \mathrm{hr}$ at $4^{\circ} \mathrm{C}$. The tissue then was transferred into phosphate buffered $30 \%$ sucrose, in which it was kept at least $48 \mathrm{hr}$ at $4^{\circ} \mathrm{C}$ to ensure cryoprotection. Lumbar spinal cords from each treatment group were processed for $c$-fos immunocytochemistry, whereas the brains of all animals were cut and Nissl-stained to verify the injection site.

\section{Effect of naloxone methiodide injection in the $\mu$-opioid receptor-like immunoreactive (MORI-IR) neurons on systemic morphine-induced antinociception}

Fifteen rats that had guide cannulae implanted two days earlier were injected subcutaneously with morphine sulfate $(5 \mathrm{mg} / \mathrm{kg})$ and $20 \mathrm{~min}$ later subjected to a formalin test. This dose of morphine has been found to consistently block the nociceptive behavior during a formalin test of this stimulus intensity (Coderre et al., 1993). The formalin behavior then was scored for $20 \mathrm{~min}$, after which naloxone methiodide $(0.36 \mathrm{nmol} / 200 \mathrm{nl})$ was injected through an intracerebral cannula into the agranular insular cortex either contralaterally $(n=11)$ or ipsilaterally $(n=4)$ to the formalin-injected paw. The injection procedure lasted $5 \mathrm{~min}$, after which the animal was returned to its cage to continue monitoring of the nociceptive behavior for an additional $30 \mathrm{~min}$. The animals were perfused $1 \mathrm{hr}$ after the injection of naloxone methiodide. This quaternary salt derivative of naloxone was chosen over naloxone hydrochloride because it has been shown to diffuse more slowly in the rat brain (Schroeder et al., 1991) and, therefore, should produce a more site-specific effect.

\section{Electrophysiological studies}

Surgery. Rats anesthetized with sodium pentobarbital (Nembutal) (65 $\mathrm{mg} / \mathrm{kg}$, i.p.; maintenance, $10-20 \mathrm{mg} \cdot \mathrm{kg}^{[\text {minus }}{ }^{1]} \cdot \mathrm{hr}^{-1}$ via a cannula placed in the jugular vein) at a depth sufficient to block pinnal, corneal, and flexor withdrawal reflexes. A laminectomy exposed the lumbar spinal cord for single-unit recording. The vertebral column was rigidly suspended in a frame and a small hole drilled over the right and, in several experiments, the left MORl-IR area target injection site. A 28 gauge drug-filled cannula was inserted into a 22 gauge guide cannula with the tip of the former extending $2 \mathrm{~mm}$ beyond the end of the guide cannula. The tip of the injection cannula was positioned stereotaxically in the agranular 
insular cortex (coordinates as above). Drugs were pressure-injected using a Hamilton $1.0 \mu \mathrm{l}$ microsyringe connected to the injection cannula by PE-20 tubing. The left hindlimb was extended, with the ventral paw upward for thermal stimulation. Core body temperature and cardiovascular status were monitored and maintained within normal physiological limits.

Peripheral stimulation and recording. Single-unit activity was recorded in the superficial and deep lumbar dorsal horn with a tungsten microelectrode (10-15 M $\Omega$ ) and amplified by conventional means. Isolated extracellular action potentials were counted with a window discriminator and fed to a computer programmed to construct peristimulus time histograms (PSTHs) (binwidth, $1 \mathrm{sec}$ ). We explicitly searched for units responsive to tactile as well as noxious thermal stimulation of the paw, i.e., widedynamic range or multireceptive-type units. Noxious thermal stimuli ( $48^{\circ} \mathrm{C}$, $5 \mathrm{sec}$ duration, $2 \mathrm{~min}$ interstimulus interval) were delivered to the center of the unit's receptive field using a feedback-regulated Peltier thermode $\left(1 \mathrm{~cm} \times 1 \mathrm{~cm}\right.$ width; rise time, $\left.12.5^{\circ} \mathrm{C} / \mathrm{sec}\right)$. Responses were quantified as the total number of action potentials during the $10 \mathrm{sec}$ period beginning with heat onset.

Experimental paradigm and data analysis. Unit responses to repeated $48^{\circ} \mathrm{C}$ heat stimuli were recorded until they were stable within $\pm 15 \%$ of the mean. Morphine ( 0.13 or $0.26 \mathrm{nmol} / 200 \mathrm{nl}$ PBS $0.9 \%$ ), $\mathrm{pH} 7.4$, then was microinjected into the RAIC contralateral to the dorsal horn unit, and neuronal responses continued to be recorded at $2 \mathrm{~min}$ intervals. If there was a noticeable change (i.e., $>30 \%$ of predrug level) in the neuronal response over time, naloxone hydrochloride $(0.82 \mathrm{nmol} / 200 \mathrm{nl})$ then was microinjected at the same intracortical site, $30 \mathrm{~min}$ after morphine administration. If neuronal responses were unaffected after morphine administration, we altered the cannula position and repeated the procedure, waiting 1-2 hr to ensure that the previous injection of morphine had been cleared. No more than three attempts were made in a given rat. In a few experiments, PBS (0.9\%), $\mathrm{pH} 7.4$, was microinjected into the RAIC and did not noticeably alter the baseline response level. Units were grouped according to those showing a decrease $\geq 40 \%$ in response after morphine administration and those showing changes of less than $\pm 30 \%$. Group mean responses were compared using the Student's $t$ test, with significance taken as $p<0.05$.

Histology. At the conclusion of the experiment, an electrolytic lesion was made through a bipolar electrode inserted into the cannula at the final cortical microinjection site. The animal was killed by perfusion through the left ventricle with $10 \%$ buffered formalin. Post-fixed $50 \mu \mathrm{m}$ tissue sections stained with cresyl violet were viewed under the light microscope, and lesion sites were plotted onto a camera lucida drawing of the section.

\section{Effects of drug treatments on motor coordination}

In another series of rats, to verify that the observed behavioral antinociception in the formalin test did not result from alterations in motor behavior, a series of motor function tests (Dunham and Miya, 1957; Kerasidis et al., 1987; Hamm et al., 1994) were performed. The absence of motor incoordination in the presence of the RAIC antinociception was ascertained by combining locomotor with paw-withdrawal testing. These five tests evaluated different aspects of motor execution and, thus, should have detected many deficits that might have passed unnoticed by a single test. (Dunham and Miya, 1957; Kerasidis et al., 1987; Hamm et al., 1994; Jasmin et al., 1994; Milan, 1994; Olmstead and Franklin, 1994; Sribanditmongkol et al., 1994).

Five days before habituation to the motor tests, a guide cannula was implanted stereotaxically above the RAIC, following the same procedure and coordinates as described above. On days 5 and 6 , the animals were habituated to the five motor tests described below (Kerasidis et al., 1987). On the day of testing, the animals first underwent five motor tests in the order presented below, followed by paw-withdrawal testing. A baseline performance score was obtained for each test. Morphine $(0.26 \mathrm{nmol} / 200$ nl) or saline then was administered through the inner intracerebral cannula, and after $10 \mathrm{~min}$, the animals were tested first for sensory behavior (paw withdrawal) and immediately thereafter for motor function. Thus, before and after drug injection, a basic motor score (on a scale of 14), a performance time on the rotarod (in seconds), and a withdrawal latency (in seconds) were obtained. For each animal, morphine was concluded to have had an effect on motor behavior if after its administration, a significant decrease of the total motor score (normal $=14$ ) or of the time (in seconds) spent on the rotarod was observed.

Walking score. The freely moving animals were placed on a flat surface $(1 \times 2 \mathrm{~m})$, and their spontaneous hindlimb movements scored as follows:
$0=$ no movement 1 = barely perceptible movement $2=$ movement but does not support weight; $3=$ animal supports weight and takes a few steps; $4=$ animal walks with mild paresis; $5=$ animal walks with no detectable deficit.

Toe spread. When holding the rat with its abdomen facing the observer, the amount of toe spread in the hindfoot was scored as follows: $0=$ no spread; 1 = partial spread; 2 = full normal spread.

Placing. The rat was grasped gently by its trunk with its hindlimbs hanging free. The dorsal and lateral aspects of each hindlimb were brushed up against the edge of a table. The ability to place each foot on top of the table was observed and graded as follows: $0=$ no attempt to place foot; 1 = weak attempt to place; $2=$ normal placing.

Catalepsy test. Rats were placed on a wire grid tilted at a $45^{\circ}$ angle with the nose pointed down. The time before the animals began to move downward or turn to face upward on the grid was recorded in seconds $(0-2 \mathrm{sec}=5 ; 2.1-4 \mathrm{sec}=4 ; 4.1-6 \mathrm{sec}=3 ; 6.1-8 \mathrm{sec}=2 ; 8.1-10 \mathrm{sec}=$ $1 ;>10 \mathrm{sec}=0)$.

Rotarod test. A rotating treadmill (Rota-Rod, Ugo Basile, Stoelting, Chicago, Il) (circumference, $18.5 \mathrm{~cm}$ ) was set at constant low speed (60 $\mathrm{cm} / \mathrm{min}$ ) before the rats were positioned on separate cylinders of the apparatus. Once all animals were in place and walking, the timers were set to zero, and the rotarod was changed to an accelerating mode so that the speed increased to $600 \mathrm{~cm} / \mathrm{min}$ over a $5 \mathrm{~min}$ period. The time until the animals were unable to keep pace with the rotarod was recorded, at which point a switch was activated to stop the timer. On the day of testing, four consecutive trials were done, and the mean of the last three trials was used for statistical analysis.

\section{Thermal paw-withdrawal test}

To evaluate the antinociceptive effect of morphine in motor coordination-tested animals, a withdrawal response to a radiant source of heat (Plantar Analgesia Instrument, UGO Basile, Comerio, Italy) was used (Yeomans and Proudfit, 1994). Two days before testing and drug injections, the animals were habituated to the Plexiglas chamber $(22$ $\mathrm{cm} \times 17 \mathrm{~cm} \times 13 \mathrm{~cm}$ ) for two sessions of $1 \mathrm{hr}$, during which no stimulus was delivered. The animals were freely mobile in a quiet environment. On the day of testing, the animals were handled for several minutes until calm. The plantar analgesia instrument was calibrated before every experimental session, and the infrared intensity set to 30 infrared units. A treatment-blind observer positioned a heat source alternatively beneath the left or right paw, with a minimum 3 min interval between stimuli to the same limb. The stimulus was always delivered at the junction of the middle and proximal third of the plantar aspect of the paw. The parameters of the heat stimulus were fixed for all experiments with a cut-off at $10 \mathrm{sec}$. A rapid, reflexive withdrawal of the stimulated limb from the source of heat was considered a positive test. Slow movement from the heat stimulus was counted as a negative result. A baseline score was determined after five consecutive tests, and the first was dropped when averaging the score. After the determination of the baseline score, the animal was removed, intracortical drugs were delivered through the cannula, and the animal was again placed in the Plexiglas cage as described above. An antinociceptive effect was concluded if pawwithdrawal latency increased significantly over baseline after morphine administration. An experimenter blind to the results of the sensory and motor tests mapped the injection sites.

\section{Fos immunocytochemistry}

The lumbar spinal cords of 59 animals subjected to formalin testing after injections of drug or vehicle into the agranular insular cortex were immunostained for the Fos antigen $(n=32$, contralateral morphine; $n=7$, ipsilateral morphine; $n=6$, contralateral saline; $n=7$, local naltrexone followed by morphine; $n=7$, contralateral naloxone methiodide after systemic morphine). The spinal cords and brains were blocked in smaller segments, and the right side was marked with a small incision using a \#11 scalpel blade. Transverse sections (50- $\mu \mathrm{m}$-thick) were cut on a freezing microtome and collected in phosphate buffer. The spinal sections were immunoreacted for the Fos antigen, whereas the brain sections were Nissl-stained to confirm the injection site. The reacted sections were dried, dehydrated in alcohol in a graded manner, cleared in xylene, and coverslipped.

To visualize Fos-like immunoreactive (FLI) neurons in the spinal cord, the avidin-biotin-peroxidase procedure was used (Hsu et al., 1981). Sections of the lumbar cord were immersed in a blocking solution made of 3\% normal goat serum (NGS) and $0.3 \%$ Triton X-100 in PBS for $1 \mathrm{hr}$ 
and then were incubated for $48 \mathrm{hr}$ at $4^{\circ} \mathrm{C}$ with a rabbit polyclonal antiserum directed against an in vitro translated protein product of the c-fos gene (a generous gift from Dr. Dennis Slamon, Departments of Hematology and Oncology, UCLA) at a dilution of 1:21,000 in PBS, 1\% NGS and $0.3 \%$ Triton X-100. This antiserum does not recognize Fosrelated antigens. The antiserum was preabsorbed in acetone-dried rat liver powder for $1 \mathrm{hr}$ at $37^{\circ} \mathrm{C}$ and $2 \mathrm{hr}$ at $4^{\circ} \mathrm{C}$ before use. After the primary antibody incubation, the tissue was exposed to a goat anti-rabbit biotinylated secondary IgG (Vector Laboratories, Burlingame, CA), diluted 1:200, and then to an avidin-biotin-peroxidase complex (Elite) complex for $1 \mathrm{hr}$ at room temperature. To visualize immunoreactivity, we used a nickel-diaminobenzidine glucose-oxidase reaction following a protocol adapted from Llewellyn-Smith and Minson (1992). Biotin dextran histochemistry on sections of cannula tracts required only exposure to the ABC complex followed by the nickel/diaminobenzidine procedure.

Quantification of Fos immunolabeling. FLI neurons were counted by a treatment-blind individual. Each section was analyzed under the microscope using bright- and dark-field illumination and drawn using a camera lucida attachment. The rostral-caudal level of the cord section was determined according to the criteria of Molander and co-workers (1984). At the L4-L5 segments, the following three nociceptive regions of the gray matter were then delineated (Steiner and Turner, 1972; Molander et al., 1984): (1) the superficial dorsal horn (SDH) (lamina I and outer lamina II or IIo), (2) the neck of the dorsal horn (lamina V and adjacent portions of laminae IV and VI), (3) the central canal (CC) area. Because there was a low variance in the mean number of FLI cells per section, six random sections were counted per animal. For each animal, the number of FLI cells in each of the three regions was counted and averaged. This allowed us to compare animals according to specific regions.

\section{Immunohistochemistry for MORl and KORl antigen}

To visualize MORI-IR and $\kappa$-opioid receptor-like immunoreactive (KORl-IR) neurons in the forebrain of two groups of three naive rats, we used rabbit antisera directed against the C-terminal portions of the $\mu$ and $\kappa$-opioid receptor amino acid sequences, respectively (Arvidsson et al., 1994, 1995a,b) (a generous gift from Dr. Robert Elde, University of Minnesota). These antisera have been shown to detect a single band on Western blots of proteins from membranes of COS-7 cells transfected with an oligonucleotide sequence coding for a 15-residue peptide identical to the 384-398 amino acids and 366-380 amino acids deduced from the cloned rat $\mu$-opioid receptors and $\kappa$-opioid receptors, respectively. These sera were applied at a dilution of 1:10,000 to $100 \mu \mathrm{m}$ brain sections from normal untreated rats. The same immunocytochemical procedure as described above for the Fos antigen was used, with the exception that the antisera were not preabsorbed with liver powder.

\section{Data and statistical analysis}

Mapping has been represented on a commercially available software package of brain maps from the atlas of Swanson (1992). All data are presented as the mean \pm SEM. The dose-dependent effect of morphine alone (injected intracerebrally) on the formalin score for all groups (A, B, $\mathrm{C}$, and saline) was analyzed with ANOVAs using Fisher's exact test. The same statistical approach was used for comparing numbers of Fos immunolabeled cells for each of these groups. Student's $t$ tests were used to compare the performance of the rats on the rotarod test and the pawwithdrawal test (four trials) before and after administration of morphine. Unless specified, the Student's $t$ test was performed with a hypothesized difference $=0$ (two-tailed). All statistical analyses were performed with StatView (Abacus Concepts, Berkeley, CA), a computer statistical analysis package. For all analyses, statistical significance was considered attained if $p<0.05$. A summary of the different experimental protocols used and the number of rats studied under each protocol are shown in Table 1.

\section{RESULTS}

\section{Identification of MORI immunoreactivity in the RAIC}

The cortical area targeted for morphine injection was identified immunocytochemically by localization of MORl immunoreactivity in the forebrain. Sections of forebrain were immunostained with an antiserum directed to the $\mathrm{C}$-terminal of the $\mu$-opioid receptor (Arvidsson et al., 1995a) and the $\kappa$-opioid receptor (Arvidsson et al., 1995b). The general distribution of MORl and KORl immunoreactivity was found to approximate those reported previously using the same antibodies or in situ hybridization (Delfs, 1994; Mansour et al., 1994; Arvidsson et al., 1995a,b). MORl-IR profiles were predominantly dendritic in appearance, whereas KORl-IR profiles were primarily somatic (Fig. $1 A-D$ ). The MORl immunoreactivity in the agranular insular cortex, a known visceroceptive area (Cechetto and Saper, 1987), made it a possible candidate for the action of morphine on nociception. The longitudinal MORI-IR profiles in this region measured $300-750 \mu \mathrm{m}$ in length and 2.0-3.0 $\mu \mathrm{m}$ in transverse diameter using a $60 \times$ lens and oil immersion. Several were observed to originate from neuron cell somata $\sim 10-14 \mu \mathrm{m} \times 17-26 \mu \mathrm{m}$ in size. The nondistinctive pattern of KORl immunoreactivity in the agranular insular cortex at this level leads us to define our target area according to the MORl-IR distribution.

The MORl-IR agranular insular area encompassed the ventral extension of cortical laminae 3, 5, and 6a as far rostrally as its dorsal displacement by the lateral and ventrolateral orbital (VLO) cortices $(+2.80$ from bregma) and conformed with the delineation of the agranular insular cortex described by Cechetto and Saper (1987) (Fig. 1A). The interwoven MORl-IR processes formed a column $\sim 1.0 \mathrm{~mm}$ in medio-lateral and $1.0 \mathrm{~mm}$ in dorso-ventral diameter, which extends $\sim 4.30 \mathrm{~mm}$ along the rhinal fissure (rf) $(+2.80$ to -1.50 from bregma). The MORl-IR region extends to the caudal limit of the agranular insular cortex, as described by Paxinos and Watson (1986). The MORl immunoreactivity became sparser and more diffuse rostrally within the VLO cortex (data not shown), thus defining its rostral boundary. An increased density of $\kappa$-opioid receptor density, however, was detected in the dysgranular insular cortex at the level of the orbital cortices (Fig. 1C).

The MORl-IR column lies dorsal and lateral to the endopiriform nucleus (en) and lateral to the claustrum. It is separated by the external capsule (ec) from the caudate-putamen (cp) and the nucleus accumbens (Acb), both of which lie medial. In other neighboring areas, including layers I and II of the agranular insular and piriform cortex, little MORl immunoreactivity was observed. The stereotactic coordinates (Paxinos and Watson, 1986) of the MORl-IR region targeted for morphine microinjection spanned from lateral $4.0 \mathrm{~mm}$ to lateral $4.8 \mathrm{~mm}$ except more caudally $(+1.50 \mathrm{~mm})$, where it spanned from lateral 2.8 to 3.3 $\mathrm{mm}$. In the dorso-ventral plane, it spanned from a depth of $5.8-6.8 \mathrm{~mm}$ except on the most rostral section $(+2.80 \mathrm{~mm})$, where the depth was from 5.5 to $6.4 \mathrm{~mm}$. At $+2.15 \mathrm{~mm}$ anterior from bregma, the midpoint of the target area, the MORl-IR area extended medially from cortical layer 6 a to layer 3 of the cortex, which bordered the rf (layers 1-2).

\section{Correlation between formalin nociceptive behavior and morphine injection sites}

Injections of morphine or saline in and around the MORl-IR area of the agranular insular cortex were followed by a formalin stimulus in the contralateral $(n=57)$ or ipsilateral hindpaw $(n=13)$. Both saline- and morphine-injected animals displayed the triphasic behavior characteristic of the formalin test (Fig. 2) (Dubuisson and Dennis, 1977). For the ensuing analysis, the animals were divided into the following three groups based on the proximity of their injection site to the MORl-IR region as evaluated by a treatment-blind individual: group A, within the MORl-IR region; group $\mathrm{B}$, within $0.3 \mathrm{~mm}$ of the MORl-IR region; group $\mathrm{C},>0.3$ $\mathrm{mm}$ from the MORl-IR region. The cannula tip positions from all cases were transcribed to the appropriate transverse brain section from a computerized version of Swanson's atlas (1992) (Fig. 3). 
Figure 1. MORl and KORl immunoreactivity in the rostral forebrain. $A$, Low-power photomicrograph of a coronal section of rat forebrain $(+2.00$ from bregma) labeled for MORl immunoreactivity. Dense labeling is present in the $\mathrm{cp}(\mathrm{CPu})$ and en. Lateral to these regions is a distinct, localized patch of extended immunoreactive processes resembling dendrites corresponding to layers 4,5 , and $6 \mathrm{a}$ of the ventral agranular insular cortex described by Swanson (1992). The boxed region depicted in $B$ includes only a portion of this area. The arrows demarcate the boundaries of the agranular insular cortex (aic), as described by Cechetto and Saper (1987). It will be noted that the ventral boundary of the agranular insular cortex extends below the rf in a line drawn from the dorsal surface of the en to the ventral surface of the invagination of the rf. This concentration of MORl immunoreactivity is found in few areas of the cerebral cortex. Scale bar, $750 \mu \mathrm{m}$. $B$, Higher-power view of the boxed area in $A$. Many extended dendrite-like processes are visible associated with a few somata (arrowheads). Measurements are cited in the text. Scale bar, $150 \mu \mathrm{m}$. $C$, Low-power view of rat forebrain $(+3.00$ from bregma) (Paxinos and Watson, 1986) labeled for KORl immunoreactivity. Heavy labeling is present dorsal to the lateral orbital $(L O)$ cortex consistent with the location of the dorsal agranular, or dysgranular, insular cortex at this level, where it descends laterally from the forceps minor of the corpus callosum (Paxinos and Watson, 1986). Scale bar, $500 \mu \mathrm{m}$. $D$, Medium-power view of the agranular insular cortex $(+2.20$ from bregma) labeled for KOR1 immunoreactivity. Scattered immunopositive cell somata are apparent within the region, characterized by MORl immunoreactivity. Scale bar, $500 \mu \mathrm{m}$.

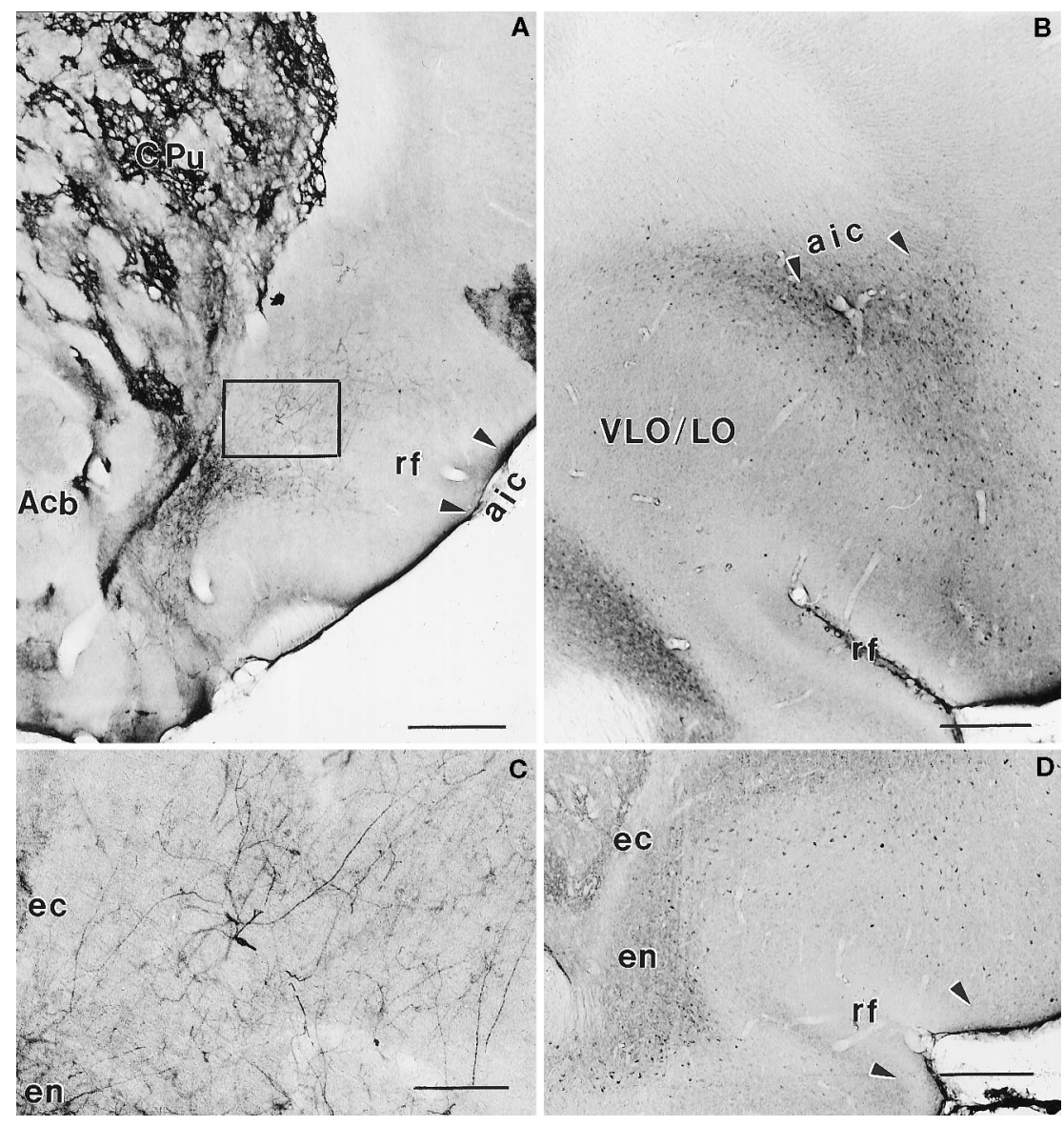

Then, for each animal, the behavioral score was correlated with the site of morphine injection. Group A $(n=13)$ had scores $\leq 0.8$ (average $=0.55 ; \mathrm{SEM}=0.097)$; group B $(n=10)$ had scores $>$ 0.8 and $<1.2($ average $=1.0 ; \mathrm{SEM}=0.036)$; and group $\mathrm{C}(n=$ 24 ) had scores $\geq 1.2$ (average $=1.5 ; \mathrm{SEM}=0.026$ ). Group A animals all had significant behavioral antinociception for the entire hour as compared with saline-treated animals $(n=6$; average $=1.6 ; \mathrm{SEM}=0.052$ ) (Fig. 2 ), whereas group B animals differed significantly for the first $25 \mathrm{~min}$ and the last $10 \mathrm{~min}$ of the test. Group C animals showed significant antinociception only during the first and last $5 \mathrm{~min}$ of the hour.

Comparative analysis with MORl immunohistochemistry demonstrated that all but two animals with strong antinociception were injected within the limits of the MORl-IR area and that antinociception was not obtained by injections caudal to +1.50 from bregma (Paxinos and Watson, 1986) within the agranular insular cortex (data not shown). The injection sites of the two animals demonstrating strong antinociception rostral to the MORl-IR region, however, were both in the agranular insular cortex dorsal to the VLO (animals 1.5 and 180), where strong immunoreactivity for the $\kappa$-opioid receptor was demonstrated (Fig. 1C). Similar antinociception was found to be reproducibly elicited in different animals by injections into the same site. Injections in the vicinity of the Acb, cp, and en had no antinociceptive effect despite the presence of $\mu$-opioid receptor immunoreactivity. When the cannulae extended into the rf (cases 1.2, 121, 127, 134, 135, 139, and 193) and morphine was injected in the subarachnoid space, no significant antinociception was observed. This result and the predictable relationship of observed effects to cannula placement are taken as

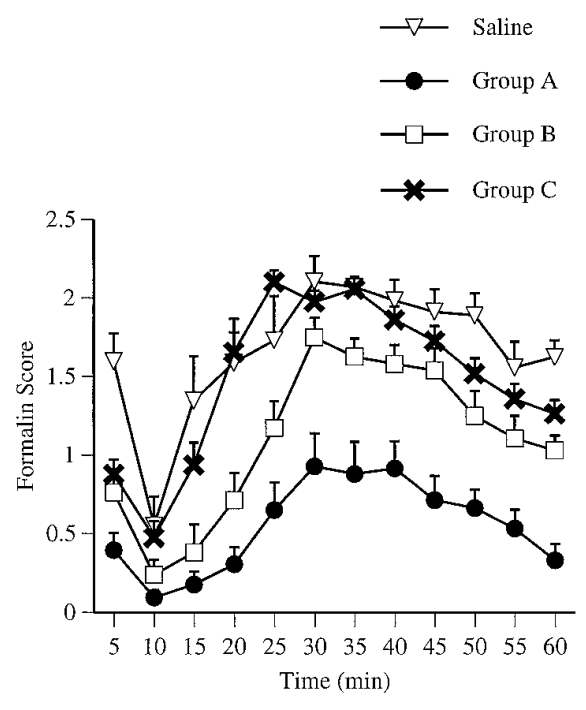

Figure 2. Formalin scoring after morphine in the RAIC. Comparison of formalin test score for animals receiving contralateral morphine or saline in or around the RAIC. Animals receiving morphine were divided into three groups based on their proximity to the MORI-IR area of the RAIC. Group A animals (average score $<0.8$ ) differed significantly from salinetreated controls throughout the hour. Group B animals (average score between 0.8 and 1.2) differed significantly over the first $25 \mathrm{~min}$ and the last 10 min. Group C animals (average score $>1.2$ ) differed from salinetreated controls during the first and last $5 \mathrm{~min}$. See text for details. 


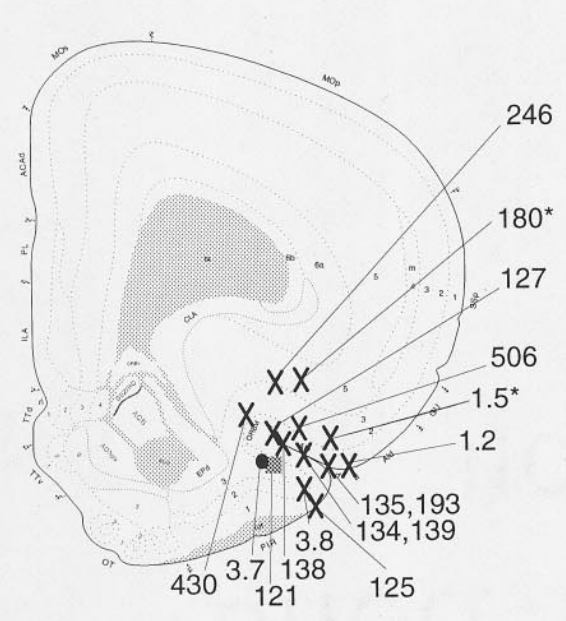

BREGMA + 2.80

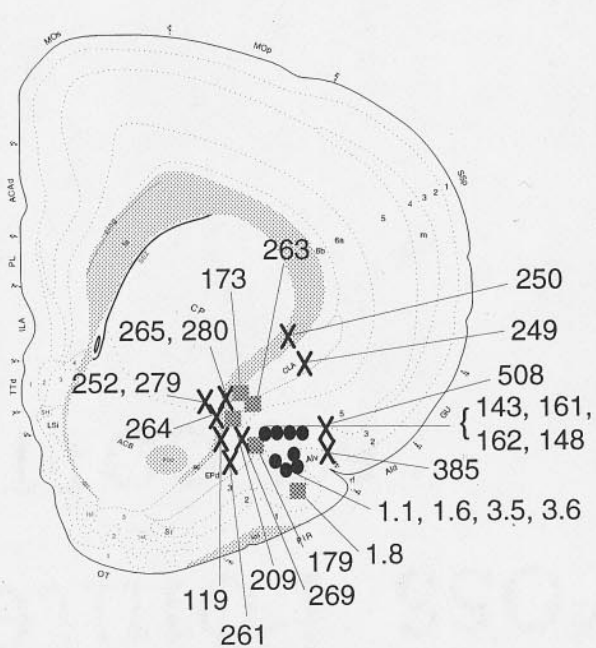

BREGMA +2.15

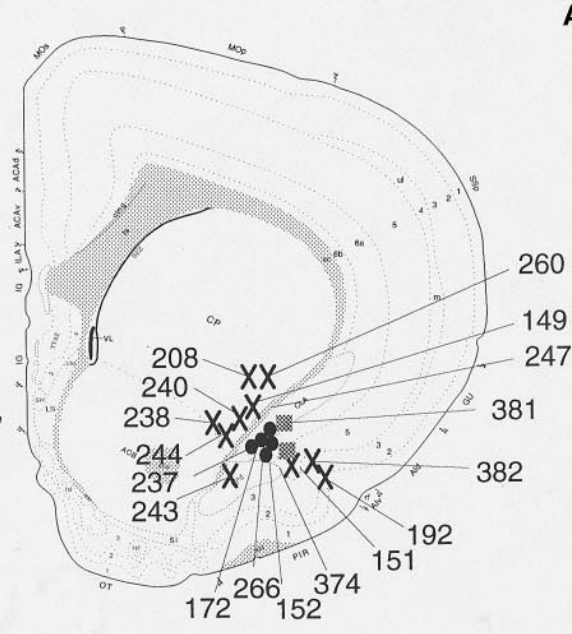

BREGMA +1.70

- WITHIN MOR1-IR AREA

WITHIN 0.3 MM OF MOR1-IR AREA

X GREATER THAN 0.3 MM FROM MOR1-IR AREA

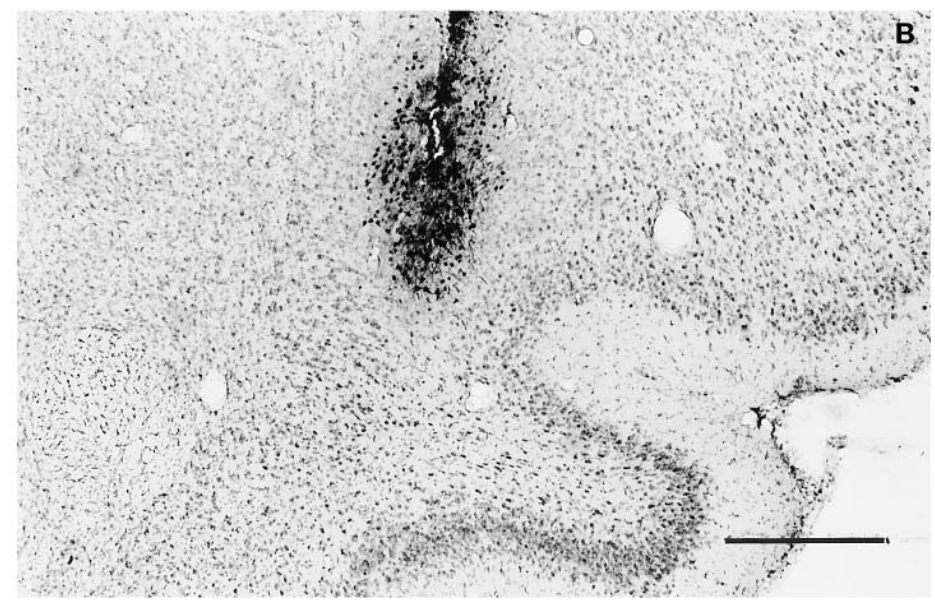

Figure 3. Correlation of injection sites with nociceptive behavior. A, This figure assembles onto three serial brain sections from Swanson's atlas (1992) the cannula mapping studies performed on cases in which morphine was administered into or around the MORl-IR area before formalin testing $(n=$ 57). Injection into the agranular insular region defined by $\mu$-opioid receptor immunohistochemistry (group A, filled circles) resulted in behavioral scores $<$ 0.8. This includes cases slightly ventral to the rf itself (see legend, Fig. 1A). Injection sites around the periphery of this region (group B, filled squares) resulted in moderate antinociception (formalin scores between 0.8 and 1.2). Injection sites $>0.3 \mathrm{~mm}$ from the MORl-IR region in various directions (group C, $X$ ) resulted in no significant attenuation of nociceptive behavior (formalin scores $>1.2$ ). Two cases (1.5 and 180) are depicted with an asterisk, because although they are not group A animals (injection within the MORl-IR area), they exhibited strong antinociception. See text for details. $B$, This photomicrograph shows a test case in which biotin dextran $(0.05 \% / 200 \mathrm{nl}$ saline) was injected into the MORl-IR area of the agranular insular cortex in a manner equivalent to that of other local drugs. Scale bar, $500 \mu \mathrm{m}$.

evidence to substantiate that the antinociception of morphine is an effect localized to the MORl-IR area and not attributable to diffusion to a distant site.

\section{Correlation between formalin behavior and Fos-like immunoreactivity in the lumbar spinal cord}

In 38 animals [group A $(n=13)$, group B $(n=6)$, group C $(n=$ $13)$, and saline-treated animals $(n=6)$ ], immunocytochemistry for the Fos antigen was performed on transverse sections of the lumbar spinal cord at the L4-L5 level (Fig. 4A-D). Figure 5 summarizes the average FLI neuron counts for the three spinal areas surveyed in morphine- and saline-treated animals: SDH, neck of the dorsal horn, and the $\mathrm{CC}$ area. When compared with the saline-treated controls, group A and B morphine-treated animals showed a significant reduction of FLI in all three spinal areas (Fig. 5). For group A $(n=13)$, the relative decrease in the number of FLI neurons was $51.4 \pm 13.5 \%(p<0.0001)$ in the SDH, $53.8 \pm 14.3 \%(p=0.0007)$ in the neck of the dorsal horn, and $47.1 \pm 16.3 \%(p=0.005)$ in the CC. In group B $(n=6)$, the relative decrease in the number of FLI neurons was $35.1 \pm 9.0 \%$ $(p<0.05)$ in the SDH, $50.5 \pm 15.7 \%(p=0.008)$ in the neck of the dorsal horn, and $64.5 \pm 16.1 \%(p=0.003)$ in the CC. In group C $(n=13)$, compared with saline-treated rats, no signifi- 
Figure 4. Correlation of Fos-like immunoreactivity in the lumbar spinal cord with nociceptive behavior. These photomicrographs depict the Fos-like immunoreactivity at the L4-L5 levels for cases $161(A), 209(B)$, and 1.2 $(C)$, which demonstrated maximal, moderate, and nonsignificant behavioral antinociception, respectively. There is a significant increase in FLI neurons in nociresponsive areas of the cord, particularly the SDH, which correlates both with nociceptive behavior and with cannula distance from the MORl-IR area (Fig. 3). D demonstrates FLI at the L4-L5 level in a saline-treated, on-site control. Fos labeling does not differ significantly from that shown in C. Roman numerals indicate spinal laminae per the classification of Rexed (1952). Scale bar, $150 \mu \mathrm{m}$.

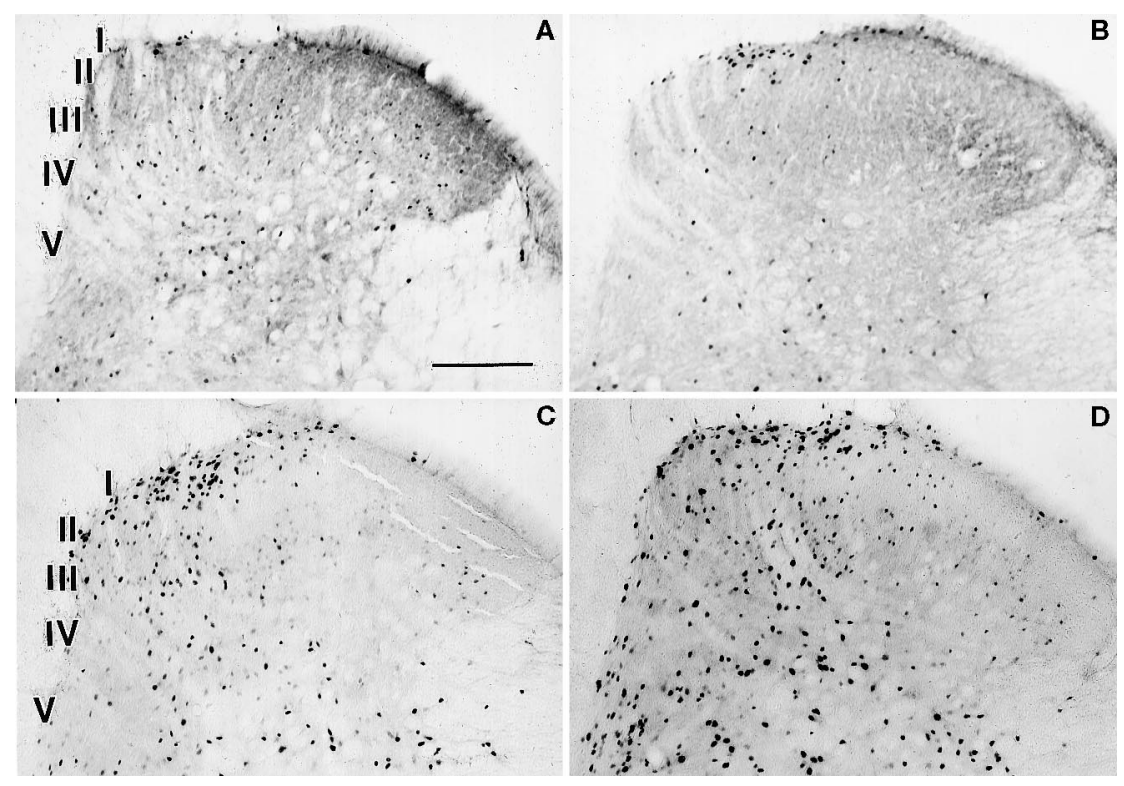

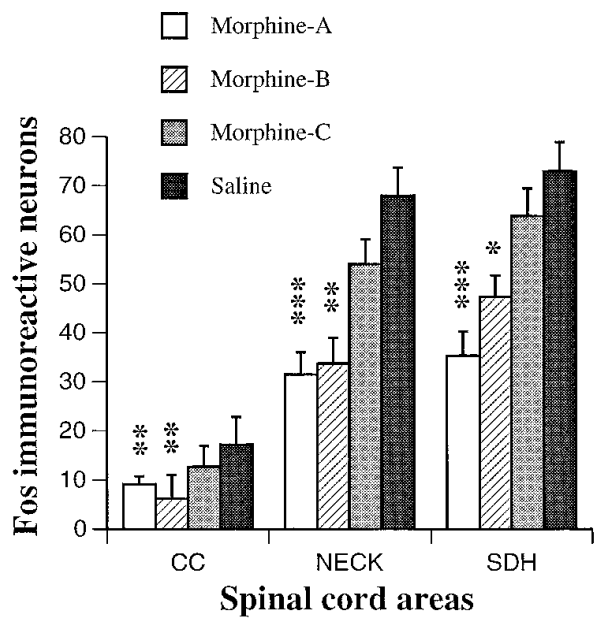

Figure 5. Fos-like immunoreactivity in nociresponsive areas of the L4-L5 dorsal horn after formalin testing. FLI neurons were counted in six randomly chosen L4-L5 sections from representatives of the four behavioral groups. Group A, $n=13$; group $\mathrm{B}, n=6$; group $\mathrm{C}, n=13$; group D (saline-treated), $n=6$. Significant differences were calculated as compared with saline-treated controls. ${ }^{*} p<0.05 ;{ }^{* *} p<0.008 ;{ }^{* * *} p<0.001$. $N E C K$, Neck of the dorsal horn.

cant difference in FLI neurons was found in any of the spinal areas in which counts were made.

The effect of local morphine injection $(0.26 \mathrm{nmol} / 200 \mathrm{nl})$ was also evaluated on formalin testing in the hindpaw ipsilateral to the injection site. Significantly reduced formalin scores were obtained with on-site $(n=3)$ versus off-site $(n=10)$ injections (average scores $=1.1$ vs $1.7 ; p<0.05)$. A reduction in FLI neurons ipsilateral to the stimulus was demonstrated in the SDH of $31.2 \pm$ $10.9 \%(p=0.007)$. Significant differences were not obtained in the neck of the dorsal horn or the CC $(p=0.05$ and 0.6 , respectively).

\section{Effect of local pretreatment with an opioid antagonist}

Naltrexone hydrochloride $(0.11 \mathrm{nmol} / 200 \mathrm{nl}$ saline $)(n=4)$ or saline $(n=3)$ was injected into the MORl-IR area 10 min before local morphine administration through the same guide cannula, after which they were subjected to formalin testing in the con- tralateral hindpaw. Preinjection of naltrexone significantly increased nociceptive behavior over saline-treated controls throughout the duration of the test, with the exception of scores at $40 \mathrm{~min}$ (data not shown). FLI was also significantly increased by $30 \pm$ $12.7 \%$ ( $p=0.0069)$ in the SDH ipsilateral to the stimulus in experimental animals.

\section{Electrophysiological studies}

For 25 units recorded in the dorsal horn of 12 rats, data were obtained for 32 microinjections of morphine into the agranular insular cortex. The depth of unit recordings ranged from 62 to 808 $\mu \mathrm{m}$ (mean $\pm \mathrm{SEM}, 414.7 \pm 52$ ), corresponding to superficial and intermediate laminae (neck) of the dorsal horn.

Morphine microinjected into the agranular insular cortex outside of the the MORI-IR area (Fig. 4) had little effect on heatevoked response levels in most spinal units either at a $0.13 \mathrm{nmol}$ $(n=5)$ or $0.26 \mathrm{nmol}(n=22)$ dose. In five instances $(16 \%$ of injection sites $),(0.26 \mathrm{nmol} / 200 \mathrm{nl}$ morphine $)$ was injected in this area and responses were reduced by $>40 \%$. For those units (Fig. $6 A$ ), the mean response level at 25-30 min after morphine administration was significantly lower compared with the mean response level before morphine administration (546 impulses; 10 sec \pm 99 SEM before morphine administration, $141 \pm 56$ after morphine administration; $p=0.009$ ). Suppression of responses increased during the $30 \mathrm{~min}$ period after morphine microinjection. Responses partly recovered during 2-20 min after naloxone injection through the same cannula (mean $461 \pm 103$ ). For the 20 units relatively unaffected by morphine, there was no significant difference between the mean responses before and 28 min after morphine microinjection. An example of a single unit responsive to morphine in the agranular insular cortex is shown in Figure $6 B$. The marked reduction in the response of the unit to heat after morphine microinjection (left vs middle PSTH) was reversed after injection of naloxone (right PSTH). Histological determination of microinjection sites confirmed that effective sites were confined to the the MORl-IR area of the agranular insular cortex.

\section{Effect of naloxone methiodide injection in the RAIC on systemic morphine-induced antinociception}

In all animals, the antinociceptive effect of systemic morphine (5 $\mathrm{mg} / \mathrm{kg}$, s.c.) was assessed by scoring formalin behavior for the first 

Before morphine

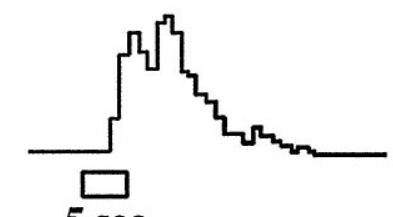

5 sec

Heat $48^{\circ} \mathrm{C}$

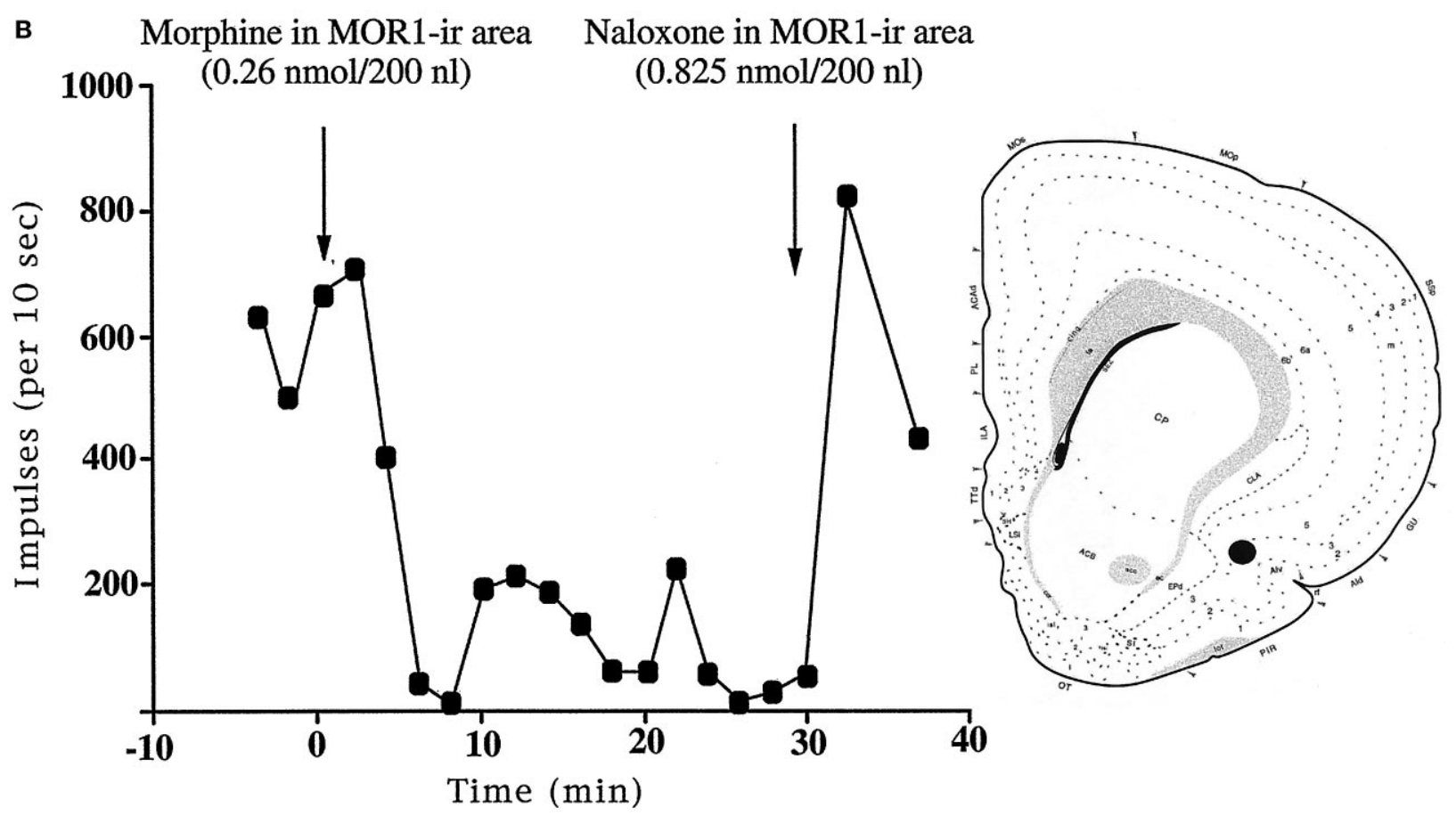

Figure 6. Electrophysiological recording of single nociresponsive units in the dorsal horn after local morphine microinjection followed by naloxone in the RAIC. $A$, This PSTH depicts the response of a single unit to local microinjection of $0.26 \mathrm{nmol} / 200 \mathrm{nl}$ morphine sulfate into the MORl-IR area of the RAIC. Suppression of the firing of a single unit in the superficial dorsal horn was reversible with naloxone hydrochloride $(0.82 \mathrm{nmol} / 200 \mathrm{nl})$ administration through the same cannula. See text for details. $B$, This graph represents the time course of firing of the same single spinal unit after local morphine administration in the RAIC. The injection site for the two drugs is shown in the inset (oval).

$20 \mathrm{~min}$ after formalin paw injection (average score $=0.2 ; n=9$ ) (Fig. 7). The average score over this period for local saline-treated controls in the MORl-IR area $(n=7)$ was $1.3(p<0.05)$, indicating that this dose of morphine was antinociceptive. Naloxone methiodide $(0.36 \mathrm{nmol} / 200 \mathrm{nl}$ saline $)$ injected either ipsilateral or contralateral to the formalin stimulus at 20 min significantly increased nociceptive behavior for the remainder of the test only when placed within the immediate vicinity of the MORl-IR area as revealed by postmortem analysis. Average formalin scores over the entire hour for contralateral naloxone methiodide were 0.8 for on-site cases $(n=4)$ and 0.08 for off-site $(n=5)(p<$ $0.05)$; average scores for ipsilateral naloxone methiodide were 1.1 ( $n=3$, all on-site). Two cases (684 and 670) of naloxone methiodide injection into the Acb contralateral to the formalinstimulated paw also demonstrated reversal of antinociception. Two cases (685 and 654) in which naloxone methiodide was injected between the Acb and the MORl-IR area resulted in no reversal of antinociception. Otherwise, injections outside the immediate vicinity of the MORl-IR area $(n=5)$ demonstrated no behavioral reversal of systemic morphine-induced antinociception.

Fos immunohistochemistry was performed on L4-L5 spinal cords of animals injected with naloxone methiodide contralateral to the formalin stimulus within $(n=3)$ and outside $(n=4)$ the MORI-IR area (Fig. 8). The number of FLI neurons was significantly increased by $31.4 \pm 18.3 \%(p<0.05)$ in the SDH of animals injected within the MORl-IR area, which had shown reversal of morphine-induced antinociception.

\section{Motor behavior after injection of morphine into the RAIC}

Fifteen morphine-treated rats underwent five motor tests: walking score, toe spread, placing, catalepsy, and rotarod. Contralateral paw-withdrawal latency to radiant heat stimulus was performed 


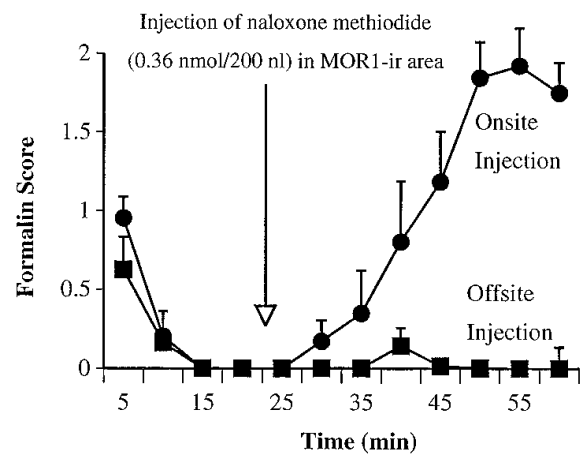

Figure 7. Reversal of behavioral antinociception of systemic morphine administration with naloxone methiodide in the MORI-IR of the RAIC. Behavioral score in animals given systemic morphine $(5 \mathrm{mg} / \mathrm{kg}$, s.c.) $20 \mathrm{~min}$ before testing, then administered local naloxone methiodide $(0.36 \mathrm{nmol} /$ $200 \mathrm{nl}$ saline) in or around the MORl-IR area $20 \mathrm{~min}$ after formalin injection into the contralateral hindpaw. Mapping of cannula tracts demonstrated that animals injected in or immediately next to the MORI-IR area $(n=5)$ showed significant reversal of the antinociception of systemic morphine administration. Animals injected outside this area $(n=6)$ demonstrated an almost total absence of pain behavior throughout the test. Behavior was not significantly different between on-site and off-site animals before administration of naloxone methiodide. A similar pattern of behavioral reversal was obtained with on-site cases after formalin injection ipsilateral and contralateral to cannula placement. See text for details.

before and after morphine injection to document the effect of morphine. All animals appeared alert and fully responsive to environmental stimuli. Six animals were injected inside and nine outside the MORI-IR area in the agranular insular cortex. The paw-withdrawal latencies before morphine injection were comparable for both groups $(4.0 \pm 0.13$ vs $4.8 \pm 0.35 \mathrm{sec}, p>0.05)$. After morphine injection, only those six animals injected in the MORl-IR area showed a significant $(p<0.05)$ increase in their paw-withdrawal latencies. When comparing the mean pawwithdrawal latency of the analgesic $(5.9 \pm 0.28 \mathrm{sec}, n=6)$ versus nonanalgesic animals $(4.1 \pm 0.16 \mathrm{sec}, n=9)$, a significant difference $(p<0.0001)$ was also found. No difference $(p<0.05)$ was found before morphine injection in either group or in off-site cases after morphine administration compared with saline-treated controls $(4.2 \pm 0.41$ before saline treatment, $4.6 \pm 0.12$ after saline treatment; $n=5)$.

The motor behavior test of rats in which morphine was injected in $(n=6)$ or around $(n=9)$ the MORl-IR area had no detectable effects on the walking score, toe spread, placing, and catalepsy (data not shown). With the rotarod, another measure of motor coordination, the average time spent walking on the rod after morphine injection was comparable $(p>0.05)$ for animals injected in the morphine-responsive area $(190 \pm 12 \mathrm{sec}, n=6)$ and those injected outside of this area $(180 \pm 16 \mathrm{sec}, n=9)$. These results were not significantly different $(p>0.05)$ than those of saline-treated controls $(180 \pm 17 \mathrm{sec} ; n=5)$.

\section{DISCUSSION}

We present evidence for a specific site in the cerebral cortex characterized by MORl immunoreactivity, the RAIC, at which morphine acts to produce potent antinociception without detectable alterations in motor behavior. The involvement of the RAIC in sensory processing is consistent with its proximity to neighboring visceroceptive segments of insular cortex (Cechetto and Saper, 1987) and the VLO cortex, a known nociresponsive area (Snow et al., 1992). This region may be involved in the antinociception produced by systemic opiates, because locally applied naloxone methiodide reverses the behavioral antinociception of systemic morphine.

\section{Defining the cortical region and showing that morphine produces antinociception locally through an opioid receptor-mediated mechanism}

A discrete pattern of MORl immunoreactivity was localized to layers 3, 5, and 6a of the agranular insular cortex with definite boundaries with regard to surrounding structures. A previous study of the distribution of the $\mu$-opioid receptor in the rat CNS using radioligand binding and in situ hybridization for $\mu$-opioid receptor mRNA (Delfs, 1994) has reported a pattern of $\left[{ }^{3} \mathrm{H}\right]$ naloxone binding in the agranular insular cortex consistent with our $\mu$-opioid receptor immunohistochemistry. The authors suggested that these cortical $\mu$-opioid receptors were located presynaptically. The elongated $\mu$-opioid receptor-bearing structures we have identified immunohistochemically, however, appear dendritic rather than axonal. The transverse diameter of these structures $(2-3 \mu \mathrm{m})$ and the association of several with cell somata make it likely that these are dendritic arborizations. The morphology of these cells may be such that a relatively low number of somata are associated with extensive dendritic arborizations, making them difficult to detect by in situ hybridization.

Systematic correlation of behavior with cannula placement confirmed that behavioral antinociception could be obtained from morphine acting within the boundaries of this region. Identical injection sites in different animals produced comparable antinociception, implying that this site is a discrete anatomic entity. Local pretreatment with naltrexone hydrochloride prevented the antinociception induced by a subsequent injection of morphine in
Figure 8. Fos-like immunoreactivity in L4-L5 spinal cords after reversal of systemic morphine-induced antinociception by local naloxone methiodide administration. Fos immunohistochemistry in one representative case in which behavioral reversal was not obtained $(A)$ of antinociception of systemic morphine administration (5 $\mathrm{mg} / \mathrm{kg}$ ) with local naloxone methiodide $(0.36 \mathrm{nmol} / 200$ nl) and another in which reversal was not obtained $(B)$. FLI was significantly increased in the SDH of cases in which reversal was obtained and cannula tracks were consistently within the immediate vicinity of the MORl-IR area $(B)$. Injections outside this cortical area (A) did not result in reversal of systemic morphineinduced antinociception, except for two cases in the Acb (data not shown). Roman numerals indicate spinal laminae per the classification of Rexed (1952). Scale bar, $150 \mu \mathrm{m}$.

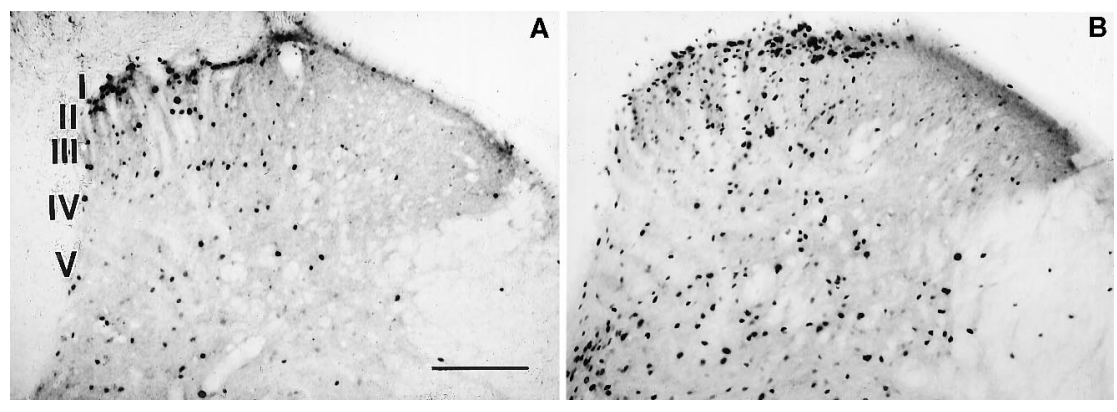


the RAIC, indicating that the antinociceptive effect of morphine is opioid receptor-mediated.

No prolonged antinociceptive effect was observed when morphine was injected $>0.3 \mathrm{~mm}$ outside of the MORI-IR area, arguing that this effect is produced locally in the MORI-IR area and in agreement with the morphine diffusion radius reported by Dickenson and Le Bars (1987). Two cases (1.5 and 180) of morphine microinjection outside of the RAIC produced significant antinociception (scores $<0.8$ ). Both cases lie within the dysgranular insular cortex rostral to the MORl-IR region $(+2.80$ from bregma), where it lies above the lateral and VLO cortices (Paxinos and Watson, 1986). At this level, there is a pronounced density of $\kappa$-opioid immunoreactivity in the dysgranular insular cortex (Fig. 1C). No other off-site case was within this KORl-IR region (Fig. 3). The antinociception demonstrated in cases 1.5 and 180 , therefore, could be mediated by this receptor population, which could constitute a second opioid responsive cortical area involved in morphine antinociception. This hypothesis would require more systematic supporting evidence than is provided here to be proven. The absence of an antinociceptive effect after injection in the $\mathrm{cp}$ in the present study may be attributable to many differences between our methods and those of other authors, including a lower dose of morphine, unilateral injections, and the use of a formalin stimulus in the present study (Jacquet and Lajtha, 1973; Yaksh et al., 1976; Anagnostakis et al., 1992; Tseng and Wang, 1992).

\section{Evidence of a role for the RAIC in systemic morphine-induced antinociception}

Injection of naloxone methiodide in the RAIC was shown to reverse the behavioral antinociception of subcutaneously administered morphine sulfate. This reversal could result, in part, from an attenuation of descending inhibitory controls by the local antagonist, because it was associated with an increase in FLI in the SDH ipsilateral to the stimulus. The lack of significant difference in FLI in the neck of the dorsal horn and the CC between on-site and off-site naloxone injection is thought to be attributable to the small sample size of each group as well as to the considerable FLI still present in analgesic animals. A relatively large dose of systemic morphine $(10 \mathrm{mg} / \mathrm{kg})$, greater than that administered in this study $(5 \mathrm{mg} / \mathrm{kg})$, is required to obtain a suppression of FLI in the dorsal horn after a formalin stimulus (Presley et al., 1990).

Although the antinociception of systemic morphine injection is attenuated by a local opioid antagonist in the RAIC, the mechanism by which the effect of morphine is reversed remains to be shown. The site-specificity of the effect, as well as the relative doses $(6.5 \mu \mathrm{mol}$ of morphine vs 0.36 of nmol naloxone methiodide) argues against systemic redistribution of the antagonist to account for the reversal of systemic morphine antinociception. Naloxone methiodide could be blocking either the local action of the systemic morphine or a local endogenous agonist, the release for which was induced by morphine. It could also be functioning to turn on a pronociceptive circuitry. The RVM, for instance, has been implicated in the production of hyperalgesia after treatment with systemic morphine followed by systemic naloxone (Kaplan and Fields, 1991).

Behavioral reversal was also obtained by injection of naloxone methodide into the Acb $(n=2)$, a structure implicated previously in opioid-mediated antinociception (Gear and Levine, 1995). Cases in which injections were placed between the RAIC and the Acb $(n=2)$, however, did not show reversal of antinociception, implying that diffusion from one site to the other does not account for the observed effects.

\section{Evidence that morphine in the RAIC activates a descending antinociceptive system}

The antinociception produced by morphine microinjection into the RAIC is proposed to result, at least in part, from the activation of a descending antinociceptive system that suppresses the activity of spinal nociceptive neurons. This conclusion is based on the following two findings: (1) the observation that in animals exhibiting behavioral antinociception, there was a concomitant reduction in the increase of evoked FLI in nociceptive areas of the spinal cord, and (2) electrophysiological data that demonstrate a naloxone-reversible reduction in firing of spinal nociresponsive neurons after locally applied morphine in the RAIC. Significantly, the observed reduction of FLI was proportional to the degree of antinociception (group A $>$ group B $>$ group C) and was present in areas of the spinal cord in which nociceptive stimuli have been shown to induce $c$-fos expression (Hunt et al., 1987; Menétrey et al., 1989); that is, rats with both maximal and moderate antinociception (groups A and $\mathrm{B}$ ) had a significant $(p<0.05)$ reduction of FLI in the SDH, the neck of the dorsal horn, and the area surrounding the $\mathrm{CC}$.

A reduction in FLI similar to that of the present study has been reported in the SDH after a $0.60 \mu \mathrm{g}$ intracerebroventricular dose of the selective $\mu$-receptor agonist [D-Ala ${ }^{2}, \mathrm{NMe}-\mathrm{Phe}^{4}, \mathrm{Gly}-$ $\mathrm{ol}^{5}$ ]enkephalin (Gogas et al., 1991). A greater reduction in FLI was reported, however, in the neck of the dorsal horn (laminae $\mathrm{V}-\mathrm{VI}$ ) in these cases than was found in the present study. This implies that the RAIC does not account for the entirety of descending inhibition produced by supraspinal opioids, and this may be particularly true of descending input to the wide-dynamic range cells present in laminae V-VI, which respond to both noxious and non-noxious stimuli (Menétrey et al., 1977).

Electrophysiological recordings also demonstrated a suppression of evoked activity in individual nociceptive dorsal horn neurons, which occurred shortly after morphine microinjection into the RAIC but not after off-site injections. The rapid onset and naloxone reversibility of this effect are consistent with a descending inhibitory circuitry from the RAIC to the spinal cord. This direct electrophysiological evidence for reduced activity in individual spinal nociresponsive units supports our data obtained with immunohistochemistry.

\section{Anatomical and functional considerations}

This is the first demonstration that the cerebral cortex can modulate nociceptive transmission at the level of the spinal cord. This is likely to occur through a multisynaptic pathway, possibly through nociresponsive brainstem relays, because direct projections to the spinal cord have not been demonstrated for this region (Miller, 1987). D'Amore and colleagues (1991) have reported $\mu$ - and $\kappa$-opioid receptor-mediated antinociception elicited from the deep prepiriform cortex. Although there may be some overlap between the RAIC and the deep prepiriform cortex, our findings differ from those of d'Amore and colleagues, who reported a strictly contralateral effect of intracortical opioids, suggesting that these regions, in fact, may be distinct. Finally, the presence of descending inhibition does not exclude other mechanisms by which morphine acting in the RAIC could contribute to analgesia; for instance, it could modulate pain through connections to limbic structures (Abbott and Melzack, 1978; Krushel and van der Kooy, 1988). 


\section{REFERENCES}

Abbott FV, Melzack R (1978) Analgesia produced by electrical stimulation of limbic structures and its relation to epileptiform after-discharges. Exp Neurol 62:720-734.

Anagnostakis Y, Zis V, Spyraki C (1992) Analgesia induced by morphine injected into the pallidum. Behav Brain Res 48:135-143.

Arvidsson U, Riedl M, Lee L-H, Nakano AH, Dado R, Chakrabarti S, Loh HH, Law P-Y, Yu L, Wessendorf MW, Elde R (1994) Cellular localization of a $\mu$-opioid receptor (mor) in rat brain and spinal cord. Soc Neurosci Abstr 20:611.3.

Arvidsson U, Riedl M, Chakrabarti S, Lee JH, Nakano AH, Dado RJ, Loh HH, Law PY, Wessendorf MW, Elde R (1995a) Distribution and targeting of a $\mu$-opioid receptor (MORl) in brain and spinal cord. J Neurosci 15:3328-3341.

Arvidsson U, Riedl M, Chakrabarti S, Vulchanova L, Lee J-H, Nakano AH, Lin X, Loh HH, Law P-Y, Wessendorf MW, Elde R (1995b) The kappa-opioid receptor is primarily postsynaptic: combined immunohistochemical localization of the receptor and endogenous opioids. Proc Natl Acad Sci USA 92:5062-5066.

Basbaum AI, Fields HL (1984) Endogenous pain control systems: brainstem spinal pathways and endorphin circuitry. Annu Rev Neurosci 7:309-338.

Basbaum AI, Clanton CH, Fields HL (1976) Opiate and stimulusproduced analgesia: functional anatomy of a medullospinal pathway. Proc Natl Acad Sci USA 73:4685-4688.

Brandt HM, Apkarian AV (1992) Biotin-dextran: a sensitive anterograde tracer for neuroanatomic studies in rat and monkey. J Neurosci Methods 45:35-40.

Carstens E, MacKinnon JD, Guinan MJ (1982) Inhibition of spinal dorsal horn neuronal responses to noxious skin heating by medial preoptic and septal stimulation in the cat. J Neurophysiol 48:981-991.

Cechetto DF, Saper CB (1987) Evidence for a viscerotopic representation in the cortex and thalamus in the rat. J Comp Neurol 262:27-45.

Coderre TJ, Fundytus ME, McKenna JE, Dalal S, Melzack R (1993) The formalin test: a validation of the weighted-scores method of behavioural pain rating. Pain 54:43-50.

Cohen SR, Abbott FV, Melzack R (1984) Unilateral analgesia produced by intraventricular morphine. Brain Res 303:277-287.

d'Amore A, Lorenzini P, Massotti M (1991) Antinociceptive action of opiates and opioid peptides after unilateral microinjection into Area Tempestas in rats. J Pharmacol Exp Ther 259:1308-1315.

Delfs JM, Kong H, Mestek A, Chen Y, Yu L, Reisine T, Chesselet M-F (1994) Expression of mu opioid receptor mRNA in rat brain: an in situ hybridization study at the single cell level. J Comp Neurol 345:46-68.

Dickenson AH, Le Bars D (1987) Supraspinal morphine and descending inhibitions acting on the dorsal horn of the rat. J Physiol (Lond) 384:81-107.

Dubuisson D, Dennis SG (1977) The formalin test: a quantitative study of the analgesic effects of morphine, meperidine, and brain stem stimulation in rats and cats. Pain 4:161-174.

Dunham NW, Miya TS (1957) A note on a simple apparatus for detecting neurological deficit in rats and mice. J Am Pharm Assoc 46:208-209.

Fields HL, Vanegas H, Hentall ID, Zorman G (1983) Evidence that disinhibition of brain stem neurones contributes to morphine analgesia. Nature 306:684-686.

Gear RW, Levine JD (1995) Antinociception produced by an ascending spino-supraspinal pathway. J Neurosci 15:3154-3161.

Gogas KR, Presley RW, Levine JD, Basbaum AI (1991) The antinociceptive action of supraspinal opioids results from an increase in descending inhibitory control: correlation of nociceptive behavior and c-fos expression. Neuroscience 42:617-628.

Hamm RJ, Pike BR, O'Dell DM, Lyeth BG, Jenkins LW (1994) The rotarod test: an evaluation of its effectiveness in assessing motor deficits following traumatic brain injury. J Neurotrauma 11:187-196.

Heinricher MM, Morgan MM, Tortorici V, Fields HL (1994) Disinhibition of off-cells and antinociception produced by an opioid action within the rostral ventromedial medulla. Neuroscience 63:279-288.

Hsu S-U, Raine L, Fanger H (1981) Use of avidin-biotin-peroxidase complex $(\mathrm{ABC})$ in immunoperoxidase techniques: a comparison between $\mathrm{ABC}$ and unlabeled antibody procedure. J Histochem Cytochem 29:577-580.

Hunt SP, Pini A, Evan G (1987) Induction of c-fos-like protein in spinal cord neurons following sensory stimulation. Nature 328:632-634.
Jacquet YF, Lajtha A (1973) Morphine action at central nervous system sites in rat: analgesia or hyperalgesia depending on site and dose. Science 182:490-492.

Jasmin L, Gogas KR, Ahlgren SC, Levine JD, Basbaum AI (1994) Walking evokes a distinctive pattern of Fos-like immunoreactivity in the caudal brainstem and spinal cord of the rat. Neuroscience 58:275-286.

Kaplan H, Fields HL (1991) Hyperalgesia during acute opioid abstinence: evidence for a nociceptive facilitating function of the rostral ventromedial medulla. J Neurosci 11:1433-1439.

Kerasidis H, Wrathall JR, Gale K (1987) Behavioral assessment of functional deficit in rats with contusive spinal injury. J Neurosci Methods 20:167-189.

Krushel AA, van der Kooy D (1988) Visceral cortex: integration of the mucosal senses with limbic information in the rat agranular insular cortex. J Comp Neurol 270:39-54.

Llewellyn-Smith IJ, Minson JB (1992) Complete penetration of antibodies into vibratome sections after glutaraldehyde fixation and ethanol treatment: light and electron microscopy for neuropeptides. J Histochem Cytochem 40:1741-1749.

Manning BH, Mayer DJ (1995a) The central nucleus of the amygdala contributes to the production of morphine antinociception in the formalin test. Pain 63:141-152.

Manning BH, Mayer DJ (1995b) The central nucleus of the amygdala contributes to the production of morphine antinociception in the rat tail-flick test. J Neurosci 15:8199-8213.

Mansour A, Fox CA, Thompson RC, Akil H, Watson SJ (1994) Muopioid receptor mRNA expression in the rat CNS: comparison to mu-receptor binding. Brain Res 643:245-265.

Marchand S, Carstens E, Burkey A, Jasmin L (1995) Antinociception induced by morphine in the cortex acts through descending inhibition on spinal transmission. Soc Neurosci Abstr 552:13.

Matthies BK, Franklin KB (1995) Effects of partial decortication on opioid analgesia in the formalin test. Behav Brain Res 67:59-66.

Menétrey D, Giesler GJJ, Besson JM (1977) An analysis of response properties of spinal cord dorsal horn neurones to nonnoxious and noxious stimuli in the spinal rat. Exp Brain Res 27:15-33.

Menétrey D, Gannon A, Levine JD, Basbaum AI (1989) Expression of c-fos protein in interneurons and projection neurons of the rat spinal cord in response to noxious somatic, articular, and visceral stimulation. J Comp Neurol 285:177-195.

Milan MJ (1994) Serotonin and pain: evidence that activation of 5-HT1A receptors does not elicit antinociception against noxious thermal, mechanical and chemical stimuli in mice. Pain 58:45-61.

Miller MW (1987) The origin of corticospinal projection neurons in rat. Exp Brain Res 67:339-351.

Molander C, Xu Q, Grant G (1984) The cytoarchitectonic organization of the spinal cord in the rat. I. The lower thoracic and lumbosacral cord. J Comp Neurol 230:133-141.

Olmstead MC, Franklin K (1994) Lesions of the pedunculopontine tegmental nucleus abolish catalepsy and locomotor depression induced by morphine. Brain Res 662:134-140.

Paxinos G, Watson C (1986) The rat brain in stereotaxic coordinates. New York: Academic.

Presley RW, Menétrey D, Levine JD, Basbaum AI (1990) Systemic morphine suppresses noxious stimulus-evoked Fos protein-like immunoreactivity in the rat spinal cord. J Neurosci 10:323-335.

Rexed B (1952) The cytoarchitectonic atlas of the spinal cord in the cat. J Comp Neurol 96:415-495.

Schroeder RL, Weinger MB, Vakassian L, Koob GF (1991) Methylnaloxonium diffuses out of the rat brain more slowly than naloxone after direct intracerebral injections. Neurosci Lett 121:173-177.

Sessle BJ, Hu JW, Dubner R, Lucier GE (1981) Functional properties of neurons in cat trigeminal subnucleus caudalis (medullary dorsal horn). II. Modulation of responses to noxious and nonnoxious stimuli by periaqueductal gray, nucleus raphe magnus, cerebral cortex, and afferent influences, and effects of naloxone. J Neurophysiol 45:193-207.

Snow PJ, Lumb BM, Cervero F (1992) The representation of prolonged and intense, noxious somatic and visceral stimuli in the ventrolateral orbital cortex of the cat. Pain 48:89-99.

Sribanditmongkol P, Sheu MJ, Tejwani GA (1994) Inhibition of morphine tolerance and dependence by diazepam and its relation to the CNS Met-enkephalin levels. Brain Res 645:1-12. 
Steiner TJ, Turner LM (1972) Cytoarchitecture of the rat spinal cord. J Physiol (Lond) 222:123P-125P.

Swanson LW (1992) Brain maps: structure of the rat brain. New York: Elsevier.

Tseng LF, Wang Q (1992) Forebrain sites differentially sensitive to betaendorphine and morphine for analgesia and release of Met-enkephalin in the pentobarbital-anesthetized rat. J Pharmacol Exp Ther 261: $1028-1036$.

Vaccarino AL, Chorney DA (1994) Descending modulation of central neural plasticity in the formalin pain test. Brain Res 666:104-108.

Wenniger J, Proctor M, Gale K, Jasmin L (1994) The analgesic effect of morphine in the piriform cortex (PC) may be mediated through the descending inhibitory control as evidence by correlation of nociceptive behavior and c-fos expression in the formalin test. Soc Neurosci Abstr 318:18.

Yaksh TL, Yeung JC, Rudy TA (1976) Systematic examination in the rat of brain sites sensitive to the direct application of morphine: observation of differential effects within the periaqueductal gray. Brain Res 114:83-103.

Yeomans DC, Proudfit HK (1994) Characterization of the foot withdrawal response to noxious radiant heat in the rat. Pain 59:85-94.

Yeung JC, Rudy TA (1980) Multiplicative interaction between narcotic agonisms expressed at spinal and supraspinal sites of antinociceptive action as revealed by concurrent intrathecal and intracerebroventricular injections of morphine. J Pharmacol Exp Ther 215: 633-642. 